\title{
Maternidad en las redes sociales de internet. Vivencias maternas brasileñas compartidas en red ${ }^{1}$
}

\author{
Motherhood on social media. Brazilian motherhood experiences \\ shared online
}

\section{Ana Luiza de Figueiredo Souza}

Universidade Federal Fluminense, Niterói, Brasil

analuizafigueiredosouzadid.uff.br

\section{Resumen}

Los debates sobre maternidad han aumentado en las redes sociales de internet, especialmente en Brasil. Por medio de narrativas personales, distintas mujeres comparten sus vivencias maternas en estos espacios, creando redes de apoyo, negociación y conflicto. El artículo explora los valores disputados a través de estas narrativas; la manera en que las redes sociales de internet hacen visibles las problemáticas de la maternidad; y cómo las narrativas personales se integran al ambiente dialógico de la cultura digital. El corpus está compuesto por nueve posts brasileños - tres en fanpages de Facebook, tres en perfiles personales del mismo sitio web y tres en blogs maternos -, con sus respectivos comentarios. En términos metodológicos, el artículo se apoya en el Análisis del Discurso Mediado por Computadora (ADMC). Las discusiones online sobre maternidad sugieren una potencial difusión del tema generada por las performances discursivas de las participantes.

Palabras clave: maternidad; narrativas personales; vivencias maternas; redes sociales de internet; ADMC.

\begin{abstract}
Debates on motherhood have proliferated on social media, especially in Brazil. Through personal narratives, different women share their motherhood experiences online, creating support, negotiation, and conflict networks. The paper aims to study: which values are disputed through these narratives; in which ways does the use of social media make the problematization of motherhood visible; and how personal narratives integrate the dialogical environment of digital culture. The corpus consists of nine Brazilian posts - three on fanpages on Facebook, three on personal profiles on the same site, and three blogs about motherhood -along with their comments. The methodology applied relies on Computer-Mediated Discourse Analysis (CMDA). Online discussions about motherhood disclose a potential of propagation, generated by participants' discursive performances.
\end{abstract}

Keywords: motherhood; personal narratives; motherhood experiences; social media; CMDA. 


\section{Introducción}

Los debates sobre maternidad a partir de una mirada más subjetiva no formaban parte de la vida cotidiana de una considerable parte de la población femenina hasta años recientes. En Brasil, el boom de los relatos personales sobre la maternidad se visibiliza a través de diferentes medios, especialmente las redes sociales de internet: plataformas de comunicación en red que surgen a partir de la segunda fase de la web 2.0, en las cuales sus participantes crean perfiles e interactúan. A menudo estas plataformas son llamadas sociales por permitir modos de comunicación en dos o más direcciones entre individuos, así como la difusión de contenidos creados por ellos (Lemos, 2002; Primo, 2007), diferenciándose de los medios masivos.

Tanto la red social de internet Facebook como los blogs maternos constituyen las principales plataformas por medio de las cuales las mujeres, principalmente las brasileñas, abordan actualmente cuestiones relacionadas a la maternidad en el ciberespacio. Dentro de esta dinámica se encuentran las madres (más, menos o in-) satisfechas con hijos (planificados o no) y las no-madres (voluntarias o involuntarias). Más allá de las páginas/los grupos de Facebook, blogs, sitios, canales de YouTube, foros de debate online y perfiles en Instagram también integran el escenario virtual en el cual se producen debates sobre lo que aquí se entiende como un concepto más amplio de maternidad: las prácticas, conflictos, valores y construcciones culturales, sociales y políticas a su alrededor.

Gran parte de la literatura académica aborda la maternidad como una institución simbólica cuya ideología está basada fundamentalmente en la cultura patriarcal. Por su parte, el término maternaje se refiere al conjunto de acciones y experiencias relativas a la rutina de cuidados con quienes se asumen como hijos. ${ }^{2}$ Sin embargo, resulta necesario pensar la maternidad y el maternaje como conceptos que afectan a todas las mujeres, al tiempo en que reflejan o influyen en el tratamiento que reciben. Por último, ellos se relacionan con la sociedad como un todo, porque tanto los niños como las no-madres en edad avanzada tendrán que ocupar espacios y servicios públicos; por lo cual se hace necesario pensar cuáles son las imágenes, las de- mandas y atribuciones que se vinculan a las mujeres que tendrán o no hijos.

Por tales motivos, el término "vivencia materna" comprende la relación de las mujeres con la maternidad, tengan o no hijos. Se trata de un conjunto de valores e ideologías relacionados con la maternidad que cada mujer - por medio de la convivencia familiar, instituciones de enseñanza, cotidiano social, producciones mediáticas y otros - adquiere a lo largo de la vida. Este conjunto ayuda a establecer el lugar que las mujeres reservan a la maternidad dentro de su planificación personal y, también, la forma a través de la cual la perciben en términos colectivos (Figueiredo Souza, 2019). A pesar de no poseer vivencia materna, los hombres pueden relatar la vivencia materna de las mujeres con quienes conviven con quienes conviven, inclusive por medio de las narrativas personales.

Escosteguy (2008) señala que la maternidad aparece constantemente como una parte integrante $y$, muchas veces, indisociable de la identidad femenina. No se trata de debatir sobre un supuesto instinto que lleva a las mujeres a ser madres, sino de comprender las estructuras socioculturales, simbólicas y tecnológicas que posibilitan la manutención (y el cuestionamiento) de determinados modelos maternos y de maternaje. Contextualizado en el escenario brasileño, el artículo destaca el papel central que las redes sociales de internet desempeñan al mediar diferentes discursos sobre construcciones de la maternidad y la no maternidad, dando visibilidad a las performances discursivas de mujeres que no son celebridades o figuras públicas.

El trabajo se propone responder una interrogante central: ¿cuáles son las narrativas sobre maternidad producidas por mujeres comunes que aparecen en medios sociales como blogs y Facebook, y qué tipo de discusiones sobre la maternidad plantean? El objetivo principal es investigar de qué modo las narrativas personales realizadas por mujeres en estas plataformas exponen las tensiones y paradojas que rodean la maternidad. Así, con base en el Análisis del Discurso Mediado por Computadora (ADMC), son analizados nueve posts que muestran distintos aspectos de la maternidad en blogs maternos y en Facebook lámbito de la producción), así como sus respectivos comentarios (ámbito de la recepción). 


\section{Marco teórico}

\subsection{Transformaciones históricas de la maternidad}

A partir del siglo $\mathrm{XVI}$, representantes masculinos de distintos sectores de la sociedad colonial y metropolitana, junto a la Iglesia Católica, anhelan la construcción de un modelo materno que incorpore los valores del matrimonio indisoluble, de la estabilidad conyugal y la valorización de la "familia legítima" (Del Priore, 2009). Así apareció la imagen de la santa-madre len portugués, santa-mãezinhal, pudorosa, casera, obediente, preferiblemente blanca y católica.

Sin embargo, había muchas mujeres al margen de las recién creadas normas maternas, de las cuales buena parte necesitaba estar ausente del espacio doméstico por períodos largos para mantenerse a sí mismas y/o a aquellos que dependían de su trabajo. Si se suman las esclavas e indígenas a esta situación, el número de brasileñas que difiere del ideal de santa-madre es mucho más significativo que el número de mujeres que lo encarna. Así comenzó una devoción popular y religiosa alrededor de aquellas que lograban ser madres, reforzada, ya en el siglo XVIII, por la diseminación de la ideología maternalista en el imaginario occidental latinoamericano.

En el siglo XIX, la medicina higienista contribuyó con el cambio de la conducta física, moral y sexual de la familia burguesa que vivía en la ciudad, concentrándose en la orientación del rol de la mujermadre. El discurso maternalista se intensificó, a pesar de que existieran prácticas maternas y femeninas opuestas a él. Quedan excluidas de los modelos hegemónicos las mujeres pobres, indígenas y negras. ${ }^{3}$ En las clases adineradas, las mujeres pasan de la figura de mujer de alcoba (plácida, pálida, dando órdenes en la casal a la de madrehigiénica. Adquieren el papel de responsables por la formación y bienestar de los hijos, teniendo a los médicos como aliados en ese proceso que, más allá de proteger la vida de los niños, principalmente los de la élite, tenía como objetivo impedir que las mujeres subvirtieran las estructuras patriarcales que beneficiaban a los hombres en el espacio social.
A lo largo de la década de 1910, el movimiento modernizador eligió a la ciencia como la principal herramienta de autoridad, siendo los médicos sus portavoces y representantes. A partir de aquí, comienza el ejercicio de la maternidad fundamentado en bases científicas, objeto de prácticas educativas propias y supervisado por médicos (Freire, 2009). La maternidad se consideraba un don vinculado a la anatomía y fisiología femeninas - que, por lo tanto, no podría ser negado-, pasible de ser perfeccionado por medio de la educación higiénica.

Las revistas femeninas se convirtieron en importantes propagadoras de los ideales higienistas y maternalistas, dirigidas a las brasileñas pertenecientes a la élite y a las de clases medias. Muchas mujeres usaron la importancia de la maternidad como función social para realizar demandas sociopolíticas y educativas. Tal apoyo en la maternidad científica segregó tanto a las no-madres como a las madres que no se encuadraban en los modelos hegemónicos.

Esto provocó que, entre los años 1960 y 1970 , aquellas comprometidas con los derechos de las mujeres muchas veces rechazaran la maternidad y los comportamientos que se les atribuían. Solo en los años 1980 se percibe la búsqueda de nuevos lugares para lo femenino, incluso valorando el cuerpo. Es en esta década que el tema de la salud de las mujeres se incluye en la agenda feminista brasileña. Si antes la maternidad era vista como marca del dominio contra el cual luchaban, ahora

\section{(...) las feministas comienzan a exigir un tratamiento específico e integral de la salud de la mujer. En busca de otra visión, menos patológica, reproductora e intervencionista, la salud se convierte en uno de los puntos de gran ataque y remodelación feminista (Carneiro, 2011, p.2).}

Como movimiento y teoría, el feminismo nacional intentó expandir el tema de la maternidad, haciéndola más respaldada y reconocida. Las corrientes feministas de los años 1990, que se enfocan en las luchas enfrentadas por diferentes mujeres, debaten sobre la construcción de lo que se entiende por identidad femenina, en un intento de ampliar los preceptos hegemónicos que la habían sustentado hasta entonces. Bajo la influencia de los nuevos 
discursos feministas, que encaran la maternidad a partir de las relaciones sociales que la implican, las redes sociales de internet se han convertido en importantes plataformas para levantar cuestiones maternas.

\subsubsection{Maternidad en el contexto contemporáneo}

En Brasil, así como en Argentina y Chile, temáticas del movimiento feminista han entrado en el debate político y en la política institucional (Avelar \& Blay, 2016). En lo que se refiere a la vida cotidiana, las redes sociales de internet son usadas para abordar cuestiones relacionadas con la violencia y las desigualdades que sufren las mujeres. Mientras los países vecinos vieron la difusión de campañas como \#NiUnaMenos y \#NiñasnoMadres en estas plataformas, en Brasil surgieron movilizaciones derivadas de colectivos feministas - por ejemplo, \#MeuPrimeiroAssédio -y de mujeres no directamente vinculadas a ellos, entre las cuales destaca \#MaternidadeReal.

Se trata del movimiento de reflejar, en los medios sociales, la maternidad de manera abierta y realista, sin ocultar sentimientos distintos al amor $y$ la satisfacción; también aborda narrativas de mujeres que no desean ser madres, desnaturalizando la maternidad. La intención es señalar sus aspectos opresores y deconstruir discursos seculares que consideran que las alegrías maternas compensan sus sufrimientos.

Desde las últimas décadas, el estímulo ocupa el lugar del deber (Sibila, 2016), generando deseos que no están exentos de la influencia de las construcciones sociales, muchas de ellas históricas. El imaginario de conquista también está presente, imponiendo un ideal de alto rendimiento que debe ser realizado individualmente a través de una lógica meritocrática (Castellano, 2018). A esto se suma el desarrollo de tecnologías de comunicación que producen nuevos soportes mediáticos y formas de interacción. En este contexto, es posible preguntarse: ¿cuáles son las continuidades y reconfiguraciones en la maternidad contemporánea con respecto a los elementos residuales del proceso de maternalización brasileño?

Del Priore (2009), en sintonía con Scavone (2004), defiende que la comunión entre el deseo institu- cional de domesticar a las mujeres para el papel de la madre y el uso que las poblaciones femeninas, a lo largo de siglos, hicieron de este proyecto, tuvo tanto éxito que el estereotipo de la santamadre proveedora, piadosa, dedicada y asexual sedimentó en el imaginario brasileño durante el período colonial y permanece en el mismo hasta nuestros días.

Sin embargo, resulta necesario prestar atención a algunas diferenciaciones. Primeramente, la culpa materna contemporánea es distinta a la moderna. Hasta la mitad del siglo XX, la culpa tenía lugar por el hecho de que la mujer deseara algo que el espacio público condenaba, dentro de una lógica en la cual la opresión formaba parte del mecanismo de funcionamiento social. Actualmente, el estímulo cumple este papel, generando deseos socialmente construidos; entre ellos el de ser una madre maleable, presente y multitareas. Lo que las madres de hoy llaman de culpa puede ser interpretado como una frustración respecto a sus fallas e incompetencias. El mecanismo que incentiva a las mujeres en la vida cotidiana es el estímulo, productor de deseos. Para tener o criar a los hijos, la madre sacrifica otro deseo, aquel que desea con menor intensidad. Sin embargo, una de las paradojas maternas reside en la faceta de la obligación- relacionada con el control y capaz de generar culpa por el no cumplimiento de las responsabilidades-, manteniendo un papel significativo, inclusive dentro de estos deseos.

La maternidad, por lo tanto, es normativa en lo relativo a la dimensión de la norma social. Hay comportamientos (on y offline) que las madres se ven forzadas a practicar, algunos establecidos por la ley, de lo contrario corren el riesgo de ser objeto de condena pública o sufrir la pérdida de la custodia de los hijos. El deseo de convertirse en madre viene de la mano de muchas obligaciones que no necesariamente la mujer está dispuesta a asumir al concretarlo. Esa normatividad también se extiende hacia las no-madres. Ciertas actitudes constituyen desvíos de lo que se espera de su comportamiento relativo al universo materno/ femenino, siendo objeto de censura, represión y asco. Varias reacciones (censura, repudio, rabia) a las prácticas opuestas a la normatividad materna se repiten entre madres y no-madres. Lo que cambia es cómo se manifiestan de acuerdo con la condición que la mujer evaluada ocupa. 
Aunque la maternidad se ha vuelto menos compulsiva en comparación con períodos históricos anteriores -especialmente con respecto al maternaje y a la posibilidad de elegir la no maternidad-. la dimensión de la toma de decisiones (Giddens, 1991) no es el único factor que afecta la vida de las mujeres. En Brasil, determinaciones legales (como la prohibición del aborto) y problemas estructurales Imisoginia institucionalizada, alto índice de violencia sexual contra las mujeres, ausencia de políticas públicas para ayudarlas o dirigidas a la educación y la planificación familiarl se mezclan con presiones morales vinculadas a la maternidad lentre ellas, la de que las mujeres tengan hijos y los amen con gran dedicación), junto a una demanda por alto rendimiento que hace que la maternidad sea más exigente y agotadora (Scavone, 2004; Mendonça, 2014; Figueiredo Souza 2020) .

Existe una paradoja más sobre la maternidad: a pesar de la influencia de presiones estéticas y prácticas culturales de apreciación de las experiencias placenteras, las obligaciones maternas tienen más importancia que los lamentos y hedonismos. Son ambigüedades de la cultura de consumo, que ofrece estímulos abundantes y contradictorios. Entre ellos el de ser, al mismo tiempo, madre y no-madre, entre obtener la seguridad de seguir el guión social de la mujer (construir una familia, ser una madre amorosal y disfrutar de mayor libertad para hacer planes que no estén vinculados a los hijos. Lo contemporáneo está marcado por el recorrido de los individuos a través de las imposiciones culturales/políticas y los deseos particulares; entre el propio camino y la intención de satisfacer las expectativas de la sociedad, en un proceso paulatino que también se refleja en las vivencias maternas y en la forma en la que éstas son abordadas en las redes sociales de internet.

\subsection{Narrativas personales sobre la maternidad en la cultura digital}

Las narrativas personales presentan modos de funcionamiento de acuerdo con los soportes y contextos en los cuales son producidas. Este artículo se propone estudiar las narrativas personales en la cultura digital, como publicaciones y comentarios - normalmente escritas en primera persona y que apelan a la dimensión de la experiencia de vida- que distintas mujeres difunden en estos espacios. Apoyándonos en la perspectiva de San Cornelio (2017), es posible agregar que las narrativas personales en el contexto digital incorporan elementos sociales y conversacionales, que en un momento dado tienen capacidad de devenir en controversia, es decir, en discusión, causar conflicto. Además de elementos textuales, puede haber imágenes, fotografías, emojis, gifs y/o videos. Se indica de esta forma la necesidad de comprender estas manifestaciones en su dimensión material.

A esto se añade la noción de que solamente es posible pensar la identidad a partir de su relación con la alteridad. La interferencia del otro modifica y construye esas narrativas, sobre todo en un momento en el que las fronteras entre lo que es o no permitido/posible de mostrarse son borrosas. Así, las narrativas son performances que pueden ser consideradas como formas de organizar el mundo, tanto para quienes las producen como para quienes las reciben, inclusive capaces de generar cierto capital social.

En esta vertiente, Orthon-Johnson (2017), basándose en la comprensión de los medios sociales como espacios de vigilancia y públicos en red, argumenta que los estudios de los llamados mummy blogs (blogs de mamás) exploran las formas en que los blogs, al ser redes sociales de internet, pueden proporcionar consuelo, apoyo y capital social para las madres. Como lectoras de estos blogs, usan la mamasfera como un sitio cultural a través del cual las identidades y papeles de la maternidad, junto a la relación madre-hijo, se (re)construyen social y digitalmente.

Orthon-Johnson (2017) concluye que el terreno digital de la maternidad puede liberar y restringir, convirtiéndose en un espacio: al para que las madres expresen/compartan frustraciones y busquen solidaridad; b) de condena y juicio público; y cl que plantea problemas éticos en la curadoría digital de la vida familiar, haciendo colapsar contextos sociales de manera significativa.

Se suma a lo anterior el hecho de que el ambiente de los medios sociales estimula una discusión pública basada en experiencias personales, en la cual la afectuosidad es importante para el posicionamiento político/colectivo de los individuos (Van Zoonen, 2012). Mientras más involucrados con determinado asunto y mientras mayor consideren 
su relevancia, los discursos y las actitudes de los sujetos sobre el tema serán más personalizados. Esto genera acciones para vincularse (Bennett \& Segerberg, 2012): la circulación de temas personales en la red basados en la negociación de marcos e identidades, considerando las relaciones y los vínculos afectivos en el momento de tomar una decisión. Así, las narrativas personales sobre la maternidad pueden ser entendidas como acciones para vincularse, ya que se basan en las experiencias personales e identidades en disputa, creando vínculos sociales.

Este contexto favorece la aproximación del sujeto a voces alineadas: discursos que confirman lo que el propio sujeto asegura y/o cree (Van Zoonen, 2012). Sin embargo, gracias a la combinación de los modelos push y pull ' en la web 2.0, las redes sociales de internet facilitan el contacto del sujeto con lo que aquí llamaremos voces disonantes: discursos que se oponen a sus afirmaciones, posicionamientos $y$, en este caso, vivencias maternas.

Las narrativas personales sobre la maternidad, serían, por lo tanto, discursos y relatos construidos desde la conjunción de la vivencia materna narrada por el/la autor/a y los recursos ofrecidos por las plataformas donde estas narrativas son realizadas. En las redes sociales de internet, la producción textual se destaca como la herramienta más utilizada en el debate sobre maternidad, siendo el público femenino el que más involucrado está en las discusiones. Tomando esto en consideración, el artículo optó por trabajar con narrativas personales vinculadas a la maternidad, escritas por mujeres.

Argumentamos que tales narrativas dirigidas hacia la maternidad son afectivas y pretenden ser efectivas. Mientras sus autoras se conmueven lo sea, son afectadas) por cierta(s) cuestión(es) referente(s) a la maternidad y/o por las otras narrativas con las que tienen contacto, también se proponen producir (y, muchas veces, producen) algún efecto en el mundo concreto a partir de sus performances discursivas. Considerando lo que escriben y cómo lo escriben, las autoras de dichos relatos tienen consciencia de que se comunican potencialmente con miles de personas. Defienden ciertos modelos maternos y femeninos, de forma tal que las narrativas personales sobre la maternidad sirven tanto para exteriorizar las opiniones como para movilizar (o afectar) al público que las lee.

\section{Metodología}

Se realizó un mapeo del escenario de discusiones sobre la maternidad en las redes sociales de internet, empezando por la red que las observaciones apuntaban como la más provechosa para la investigación: Facebook. Apoyándonos en el tipo de muestreo de "bola de nieve", en el que se identifican informantes que conducen a la investigadora a otros informantes (Hammersley \& Atkinson, 1983), el flujo de asociaciones derivadas (en portugués, fluxo de associações derivativas) admite también agentes no humanos para conducir a otros agentes que realicen la función de informantes.

En esta investigación, las páginas web en las que se discuten aspectos de la maternidad conducen a otras que presentan la misma propuesta, que fueron añadidas a la muestra siempre que reunieran los siguientes requisitos: al proponerse problematizar la maternidad; b) estar activa; cl poseer más de diez mil seguidores; d) tener participación del público, es decir, que el público interactúe con la mayor parte de las publicaciones de la página web; en tal caso, ejemplos con pocos seguidores serían considerados. Para investigar estas características, se realizó un breve estudio exploratorio de las secciones Página principal, Sobre y Publicaciones de cada página web. El esquema en la figura 1 presenta una síntesis del método.

A partir de las páginas web, los blogs y otras plataformas identificadas fue posible mapear las redes sociales de internet más significativas que problematizan la maternidad en Brasil, así como averiguar sus fechas de creación y el tipo de contenido publicado. Tal mapeo contribuyó con la producción del corpus del trabajo, como se muestra en el cuadro 1, compuesto por tres conjuntos relacionados con los tipos de material encontrados mayoritariamente en el campo. Se trata de un mapeo representativo del contexto de discusiones sobre la maternidad que fue monitoreado durante tres años. La visibilidad (cantidad de reacciones, comentarios y cantidad de veces compartidos), la implicación del público (interacciones con los posts) y la fecha de publicación de los posteos también se han considerado como criterios de selección para definir las unidades de análisis del corpus. El período definido fue desde 2016 hasta el segundo semestre de 2018, durante el cual se desarrollaron la investiga- 
ción previa y la tesis de maestría en la que se basa este artículo; recorte en el que tanto la producción como la difusión de publicaciones que problematizan la maternidad en las redes sociales de internet fueron notablemente más altas que en otros períodos hasta el final de la referida investigación.
Para analizar el corpus, la investigación se ha inspirado, de forma más sucinta, en los preceptos del Análisis del Discurso Mediado por Computadora (ADMC) - en su expresión original, creada por Herring (2012), Computer-Mediated Discourse Analysis (CMDA). El método propone la división del lenguaje

Figura 1: Esquema del flujo de asociaciones derivadas

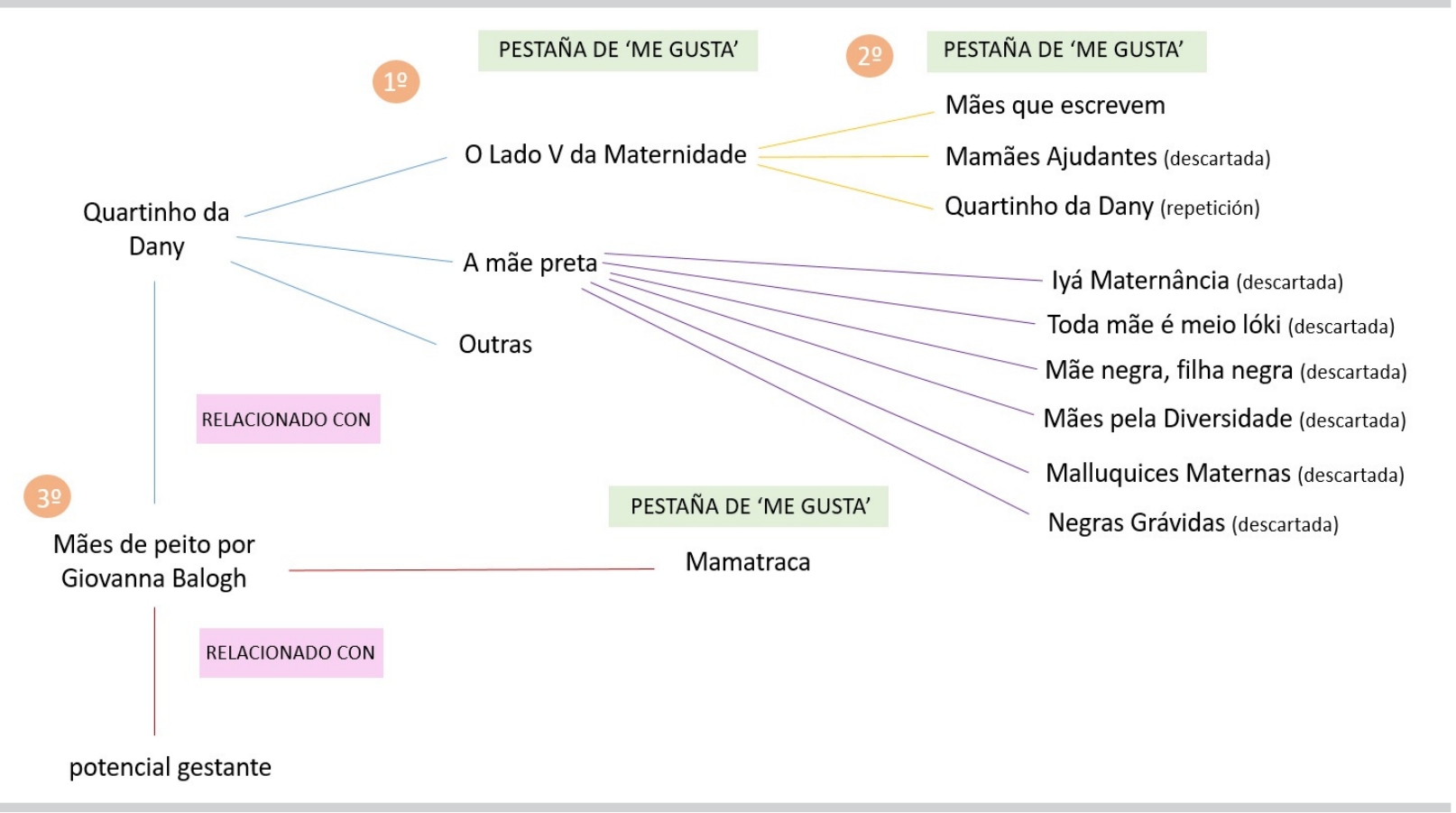

Fuente: Elaboración propia

Cuadro 1: Corpus de investigación

\begin{tabular}{|c|c|c|}
\hline $\begin{array}{l}\text { Posts en fanpages } \\
\text { de Facebook }\end{array}$ & $\begin{array}{l}\text { Publicaciones en perfiles } \\
\text { personales de Facebook }\end{array}$ & Posteos en blogs maternos \\
\hline $\begin{array}{l}\text { 'Solo podemos mostrar la maternidad } \\
\text { como una experiencia de plenitud } \\
\text { y felicidad, critica psicoanalista' } \\
\text { - HuffPost Brasil, } 18 \text { sep. } 2016\end{array}$ & $\begin{array}{l}\text { Desafío NO aceptado - } \\
\text { Juliana Reis, } 15 \text { feb. } 2016\end{array}$ & $\begin{array}{l}\text { Un día de cada vez - Vida } \\
\text { sem Filhos, feb. } 2013\end{array}$ \\
\hline $\begin{array}{l}\text { “Me arrepiento de ser madre” - } \\
\text { BBC News Brasil, } 09 \text { dic. } 2016\end{array}$ & $\begin{array}{l}\text { Contiene spoiler de la vida de } \\
\text { madre - Júlia Rocha, } 19 \text { oct. } 2017\end{array}$ & $\begin{array}{l}\text { Ser madre no es suficiente para } \\
\text { mí - Bossa Mãe, } 23 \text { oct. } 2017\end{array}$ \\
\hline $\begin{array}{l}\text { Mujeres que no tienen hijos - } \\
\text { Quartinho da Dany, } 08 \text { jul. } 2017\end{array}$ & $\begin{array}{l}\text { Pronto completaré } 38 . \\
\text { No tengo hijos - } \\
\text { Fhoutine Marie, } 6 \text { feb. } 2018 \\
\text { Contradestinatario }\end{array}$ & $\begin{array}{l}\text { No lea mi blog si está buscando una } \\
\text { razón para no tener hijos - Tudo } \\
\text { Sobre Minha Mãe, } 27 \text { mayo } 2014\end{array}$ \\
\hline
\end{tabular}


mediado por la computadora en cuatro niveles (Estructura, Significado, Gestión de Interacción, Fenómeno Social), compuestos por tres elementos: cuestiones que afloran; el fenómeno que va a ser analizado; el método que se puede usar para investigarlo. En este artículo nos interesó abordar los niveles del Significado y Fenómeno Social.

El primero está relacionado con las pretensiones que tenemos cuando hacemos uso del lenguaje mediado por la computadora, cómo son comunicadas y qué resulta de esa comunicación. Para estos fines, se observa el significado de las palabras, de los actos del habla y los cambios de significado a través del uso de la semántica, prestando atención a sus manifestaciones y efectos prácticos. El nivel del Fenómeno Social se relaciona con las dinámicas sociales, relaciones de poder y conceptos tales como influencia, identidad, comunidad y diferencias culturales/sociales. Para esto, debemos tener en cuenta las expresiones lingüísticas que denotan estatus, conflictos, negociaciones e impresiones generadas, además de observar el estilo y particularidades de los discursos investigados.

Para estudiar las unidades de análisis del corpus, primero se trabajó sobre el eje de producción. Después, se examinaron los principales comentarios (que contenían narrativas personales) en el post analizado, realizando un breve análisis de las autoras basado en las informaciones disponibles en sus perfiles. La figura 2 ejemplifica cómo se hizo el análisis de los posts seleccionados y los comentarios más importantes. Las reacciones ${ }^{5}$ que cada uno de estos recibió también fueron consideradas para interpretar la recepción del público.

Cabe señalar que las publicaciones se realizaron en modo público, lo que hace posible desarrollar una discusión científica sin requerir la autorización de la autora.

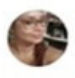

Fhoutine Marie

6 de fevereiro de 2018 :

Em breve eu vou completar 38 anos. Eu não tenho filho. Melhor dizendo, eu sou uma mulher cis hétero em um relacionamento longo e com o aparelho reprodutor saudável que não tem filho. Ou seja, eu não tive filho porque o momento de tomar a decisão de colocar uma pessoa no mundo não chegou. Ou melhor, eu não tive filho porque eu não quis.

Antes que alguém diga que ainda dá tempo, eu respondo que sei como funciona o meu corpo e que ainda não entrei na menopausa. Eu sei que tem tempo. Tem tempo, tem corpo funcionando bem pra essa finalidade, tem marido bacana. $\mathrm{O}$ que não tem: vontade da minha parte.

Antes que alguém me diga "mas é tão bom", eu respondo que não đuvido. As pessoas da minha idade estão grávidas, tem filhos pequenos,

adolescentes, entrando na faculdade ou mais de uma categoria. Eu vejo a alegria dos meus amigos que tem filho, mas não é pra mim. Eu não odeio criança, ao contrário, eu me dou muito bem com crianças. Eu não gosto muito de adolescente, mas até ai nem pai e mãe de adolescente gosta muito de adolescente.

A questão é que eu não tenho a menor vontade de ficar grávida ou de cuidar de uma criança todos os dias da minha vida e pelos próximos anos. Isso não quer dizer que eu seja uma dessas childfree que não quer conviver com crianças. Na minha idade é inevitável porque a maioria das pessoas tem filho. Crianças são pessoas como quaisquer outras, só possuem uma lógica diferente. Com a vantagem de serem mais legais e bonitinhas que a maioria das pessoas.

Como mulher cis que optou por não ter filhos eu penso todos os dias no privilégio que é poder não ter filhos num país que nos obriga a levar adiante uma gestação que você não quer. Ou é isso ou se encher de hormônio pra garantir. Eu me encho de hormónio. Eu penso também no quanto me perturba as pessoas que me cobram filhos e imagino o quanto de perturbação as mães aturam porque estão cansadas ou solitárias demais pra mandar todo mundo pro inferno.

Enfim, eu estou escrevendo isso porque eu sinto que precisamos falar disto com mais honestidade. Maternidade compulsória, solidão materna e nãomaternidade. Porque o patriarcado tai pra nos tratar como encubadoras e pra tratar que se recusa a ser mãe como mulheres menores, defeituosas, egoistas e pra dizer pras que são mães 'virem-se, quem pariu Matheus que o embale"

C): $3.5 \mathrm{mil}$

51 comentários 707 compartilhamentos
Dani Amiga, eu tenho a Clarice e estou feliz com ela. Mas desde que me assumi com um companheiro mara e 13 anos mais novo que todo mundo pergunta: "mas e um filho de vcs 2?". Já teve até quem dissesse que seria injusto com ele eu não ter outro filho. E comigo? Tem justiça pra mãe? Pois é.

A verdade é que sempre tem que nos julgue pq sempre esperam mais e mais de nós.

Permaneçamos felizes como somos e tranquilas em nossas escolhas. Isso é justiça.

Curtir - 16 sem

(1) : : 53

Heloisa

Filho tem que ser escolha! Não tá afim, nāo tenha mesmo! Tá certíssima! A vida é sua, e quando a gente tem filho, a vida muda muito.

Curtir - 16 sem

lalandalu

Eu acho que as pessoas localizam muito a maternidade na criança e não no fato de que maternidade se trata de um papel social imposto as mulheres. Ser mãe se trata muito mais de controle social do que a experiência em si. E não sobre gostar ou querer ter crianças por perto. Até pq, tanto a infância quanto a adolescência, comparada com a fase adulta é uma parte bem pequena da vida de qualquer individuo. E maternidade ultrapassa a dimensão do choro e do acordar cedo. Acho que temos que nos perguntar. afinal, o que é ser mãe? E por que somos mães? E para quê ou quem?

Curtir - 15 sem 


\section{Resultado de los análisis empíricos}

En las discusiones analizadas, la función "editar publicación" es bastante utilizada para corregir errores de tecleo o añadir argumentos, lo que sugiere que los debates fueron realizados de manera simultánea, sin que las participantes reflexionaran mucho sobre lo que escribían. Tal acto genera narrativas más emotivas y espontáneas. Aun así, las autoras vuelven a los comentarios para perfeccionarlos o corregirlos. Tal edición revela que las mismas continúan a la par de los debates y también se posicionan a partir de las reacciones a lo que escriben.

Resultaba poco probable que hubiera en las discusiones observadas debate sobre la maternidad sin que ocurriera la interacción entre madres y no-madres. La investigación también encontró puntos en común entre las narrativas que parten de experiencias particulares. Hay ejes discursivos presentes en la mayor parte de los comentarios de madres (amor por los hijos). Otros son mayoría entre los comentarios de las no-madres (considerarse incompletas). También es posible encontrar elementos y situaciones que se repiten en ambas narrativas (presión de la familia por tener hijos). Esto denota que existen prácticas y concepciones que afectan a estos dos grupos y, por lo tanto, afectan a todas las mujeres.

Entre los ejes discursivos más destacados, se encuentra el de las obligaciones y recriminaciones de la maternidad, en el cual se manifiestan denuncias de agotamiento materno: "Privación del sueño, estropear el cuerpo, perder la libertad y la autonomía, no es nada romántico". Las narrativas sobre los desafíos maternos pueden estar asociadas al imaginario de victoria - la jornada de la vencedora que supera los obstáculos y resiste a las dificultades para conquistar sus objetivos, siguiendo la lógica de los méritos (Castellano, 2018): “Estoy al nivel de lo que la gente concibe como una 'gran madre'. Me levanto muy temprano, hago café, [mis hijos] siempre están limpios y perfumados, ayudo con la tarea, trabajo 12 horas al día". Estas narrativas denuncian que los criterios para ser considerada una buena madre son exigentes, alienados con efectos considerados positivos por el capitalismo liberal (Mendonça, 2014).
Otro eje bastante fuerte es el de las vivencias personales. Muchas narrativas revelan desconfianza ante las informaciones difundidas por agentes mediáticos como los programas de televisión y blogs/ grupos de información, generando acciones conectivas (Bennett \& Segerberg, 2012) para informar a otras mujeres sobre lo que consideran la verdadera maternidad, a partir de sus propias narrativas: "Maternidad real no es la que se muestra en las telenovelas, es la que viven las madres". Sin embargo, las vivencias maternas personales poseen un cierto grado de mediación, pues también son construidas a partir de relatos y experiencias de otras mujeres sobre la maternidad. Los posts que las debatientes elogian y comparten fueron realizados en dispositivos mediáticos, elegidos por las propias autoras.

Ante este escenario, las redes de apoyo se generan entre mujeres cuyas voces se sienten alienadas. Las discusiones tienen un carácter mucho más auto-afirmativo y de desahogo que de concientización o de aclaración: "Pues soy bisabuela, tuve cuatro hijos y puedo hablar, eres muy romántica y espero que seas madre pronto, entonces podrás decir algo. Por ahora, boca cerrada". Esto, inclusive, revela los límites del discurso de sororidad alianza entre mujeres basada en la empatía-, de los actuales movimientos feministas. La sororidad solamente existe entre las mujeres que poseen posiciones similares. El derecho a hablar se transforma en un recurso para descalificar o contrarrestar vivencias maternas diferentes, con el fin de criticar argumentos o voces disonantes. En este sentido, el terreno digital de la maternidad se convierte en un espacio para que las madres encuentren solidaridad en relación a lo que publican (voces alineadas) o en un ambiente de juicio público sobre lo que expresan (voces disonantes), similar a lo que plantea Orthon-Johnson (2017).

La visibilidad es importante para las autoras de las narrativas publicadas: "Soy madre, la maternidad es un infierno, me gustaría que más personas supieran esto antes de juzgar". Vemos una característica de los sujetos contemporáneos que se extiende hacia los medios digitales (Sibilia, 2016): demostrar que sus sentimientos y experiencias son reales, que ocurren, a pesar de no tener un lugar destacado en los medios o en el imaginario colectivo. La intencionalidad performática de las participantes de 
la mayoría de los debates parece más relacionada con el hecho de ser reconocidas por personas con su mismo punto de vista que el de convencer - o hacer entender su argumento - a quienes poseen una posición opuesta. Cada una deja el registro de su vivencia materna, que va a ganar un "me gusta" y reacciones de "me encanta" de aquellos que están de acuerdo con el argumento, un "me divierte" o un "me enoja" de los que discrepan con el mismo.

Esta dinámica argumentativa muestra el ambiente de las redes sociales de internet como predominantemente de confirmación, en vez de ser espacios para la objeción, conforme también enunció Van Zoonen (2012). El tono emotivo del contenido que busca ser efectivo se refleja en las polarizaciones, la agresividad y en un cierto binarismo que suele manifestar las posiciones de quien publica el comentario.

La construcción del valor de autenticidad para la vivencia materna es otro de los aspectos significativos entre estas narrativas, ya sea por compartir situaciones enfrentadas por madres o no-madres, o por demostrar conocimiento sobre las facetas de la maternidad o de la no maternidad: "Hablando como alguien que no tiene y no quiere hijos, sé que mucha gente piensa que somos monstruos". En las narrativas, el lugar de habla es fundamental. A partir de él y de la propia vivencia materna, las participantes de las discusiones urden sus relatos y evalúan el contenido de los otros comentarios. A pesar de esto, el lugar de habla no es un factor determinante para aprobar o descartar las narrativas compartidas. Muchas veces, quien habla no importa tanto como lo que dice, reforzando la dinámica de las voces alineadas y la negociación performática presente en las interacciones. Pero si alguien, ajeno al grupo al que una de las participantes pertenece, expresa un discurso que genera discordia con lo que ella o su grupo defienden, la inadecuación del lugar de habla y del contenido del argumento son rebatidos con más agresividad: "Ahí viene la mamá hablando mierda de quién no es mamá".

Otro de los ejes presentes es el de las valoraciones predominantes sobre la maternidad: "Criamos a nuestros hijos para una disputa, una carrera capitalista que comienza cuando el bebé todavía está en el útero"; "Hijo no es excusa para no trabajar o estudiar"; "Quiero a mis hijos, hago todo por ellos, es difícil, pero el amor solo aumenta"; "Estoy segura de que nací para ser madre, mi vida solo tuvo sentido con la llegada de mis hijos." Es posible notar, en los modelos maternos y de maternaje descritos, la influencia de concepciones tradicionales (Del Priore, 2009; Costa ,1999; Freire, 2009) combinadas con demandas de optimización (Mendonça, 2014; Sibilia, 2016; Castellano, 2018), respondiendo a nuevas exigencias y definiciones femeninas que, en buena parte, derivan del mercado.

El último de los ejes más significativos es el de las paradojas maternas, las disímiles contradicciones que son parte de la maternidad: "Una mezcla de felicidades, tristezas y culpas". De acuerdo con lo presentado aquí, tal vez la gran paradoja materna sea que, a pesar de lo exigente y desgastante que es dentro de una cultura patriarcal, constituye un camino más previsible y seguro en términos socioculturales, sobre el que las mujeres poseen referencias (familiares, sociales, mediáticas) desde muy jóvenes. Un emprendimiento por medio del cual gran parte de ellas cree conquistar importancia y una posición social, tal como se percibe en algunas narrativas personales publicadas: "Solo comencé a ser tratada como adulta después de tener a mi hija. Entonces, por agotador que sea, siento que soy parte de algo más grande". De forma contradictoria, la maternidad termina siendo una experiencia social y, sobre todo, personalmente gratificante para la mayoría de las brasileñas que la critican en las redes sociales de internet.

\section{Conclusiones}

Nunca hubo leyes que obligaran a las mujeres a ser madres en el Brasil colonial. Lo que existía era la coerción social, vinculada a la interiorización del deber moral de ser madre. Las mujeres sólo alcanzaban acceso a ciertos derechos y algún reconocimiento público si tenían hijos. La maternidad sigue siendo la forma a través de la cual muchas brasileñas adquieren reconocimiento en sus respectivos entornos, especialmente en las comunidades más pobres (Scavone, 2004). Sin embargo, en el Brasil de hoy, la legislación obliga a las mujeres a ser madres al no permitir que se realice el aborto. A pesar de haber organizado grandes manifestaciones a favor de su despenali- 
zación, no sólo en Brasil, sino también en Chile y Argentina, no fueron suficientes para cambiar las leyes actuales.

No en vano los colectivos y las iniciativas feministas han aprovechado las plataformas digitales con gran potencial de difusión para convocar a las mujeres para protestas contra determinaciones estatales que las oprimen. Pero, en Brasil, las discusiones virtuales relacionadas con las inequidades de género tienden a tener un enfoque personalista, especialmente en los debates sobre la maternidad en las redes sociales de internet. Aunque los movimientos feministas en el espacio digital ciertamente influyen en el intercambio de narrativas que problematizan la maternidad, las participantes en estas discusiones generalmente no integran grupos feministas, muchas de ellas ni siquiera se reconocen como tales. Apuntan más a las soluciones relacionadas con el alcance individual (como no juzgar a las madres o las que no quieren hijos) que a las medidas políticas. Aun así, reconocen que existen estructuras que hacen que la vivencia femenina $-y$, por extensión, lo que se relaciona con la maternidad- sea más complicada.

Dentro de un contexto misógino, es probable que una fracción significativa de las brasileñas sea víctima de alguna violación de sus cuerpos o voluntades; así como de los frecuentes atentados a los derechos reproductivos femeninos por parte de los poderes públicos. Crece, por lo tanto, la urgencia para que las mujeres logren decidir sobre si desean o no ser madres, de tal manera que esta decisión surja de una elección propia, y no sea resultado de imposiciones o privaciones. Una vez que se toma conciencia de la hostilidad que existe en Brasil con relación a las mujeres, se hace posible comprender el carácter enfático y emotivo de las narrativas personales que las mismas producen sobre la maternidad en las redes sociales de internet - plataformas hace mucho incorporadas a la vivencia cotidiana. Podemos considerar estos imperativos como modos de defender la posibilidad de tomar decisiones sin la influencia de estructuras opresoras.

Las narrativas en red hacen colapsar la coyuntura en la que se insertan las vivencias maternas narradas y los valores que defienden sus autoras. A través de ellas, como ya ha notado Orthon-Johnson (2017), las secciones de comentarios se convierten en espacios para desahogo, queja y búsqueda de apoyo entre mujeres con posicionamientos semejantes, siendo un ambiente de conflictos y cuestionamiento entre aquellas con posiciones distintas.

Más allá de ser o no madres, las mujeres buscan (poder) definir el curso de sus posicionamientos maternos de acuerdo con las especificidades de las condiciones en las que se integran. Ya que no existe otra opción que la de elegir (Giddens, 1991), y es necesario ser coherente con relación a estas elecciones, que sean realizadas de forma más libre y personalizada, independientes de los modelos maternos y de maternaje normativos; una demanda capaz de expandirse a través de diferentes públicos por medio del intercambio de la vivencia materna de mujeres que la visibilizan en sus performances discursivas en las redes sociales de internet.

\section{Notas}

1. Este artículo se basa en la tesis de maestría Me deixem decidir se quero ou não ser mãe!: Narrativas pessoais de mulheres sobre a maternidade nas mídias sociais, ganadora del Premio Compós de Tesis de Maestría y Doctorado 2020. Ver https://bit. ly/31jLOEs

2. El término maternaje se utiliza en áreas como la psicología para designar el cuidado de niños realizado por madres u otros cuidadores. Consiste en la traducción al español de mothering, término compuesto por la fusión del verbo to mother con el sufijo ing, que indica acción y proceso continuo en inglés, por lo que Mendonça (2014, p. 26) eligió la palabra maternagem como su traducción al portugués. En ella, el sufijo latino agem expresa acción o resultado de acción. Por alinearse al razonamiento de la autora y siendo el español también un idioma latino, este artículo usa el término maternaje. 
3. Muchas veces, se convertían en nodrizas. A finales del siglo XIX, la regularización del servicio ocurrió en provincias importantes. Sólo podrían ejercerlo después de un examen médico que certificara su salud. Con la llegada de alimentos industrializados para la nutrición infantil, la Ley Áurea y las diferentes reformas urbanas que afectaron a la población más pobre, la práctica de las nodrizas fue reducida, aunque continuó hasta años posteriores a 1930.

4. Según Primo (2007), cuando los actores sociales se encuentran y se relacionan con contenidos y usuarios que buscan por iniciativa propia, también son abordados por propagandas, sugerencias y, como vemos en este artículo, narrativas que no esperaban encontrar en las redes sociales de internet movilizadas por ellos.

5. Recurso que pasó a integrar las funciones de Facebook en febrero de 2016. Además del tradicional "me gusta", los usuarios pueden interactuar en las publicaciones de los otros con "me encanta" lícono de corazón), “me divierte" (emoji de risas), “me asombra" (emoji de admiración), "me entristece" (emoji de llanto), "me enoja” (emoji de rabia).

\section{Referencias}

Avelar, L. \& Blay , E. A. (Orgs.). (2016). 50 Anos de Feminismo: Argentina, Brasil e Chile. A Construção das Mulheres como Atores Políticos e Democráticos. São Paulo: Edusp.

Bennett, W. L. \& Segerberg, A. (2012). The logic of connective action. Information, Communication \& Society, 15(5), 739-768. doi: 10.1080/1369118X.2012.670661

Carneiro, R. (2011, julio). Feminismos e Maternidades: (des)encontros e (re)significados. Subjetividades Maternas e Feministas em Questão. Trabajo presentado en XXVI Simpósio Nacional de História, São Paulo.

Castellano, M. (2018). Vencedores e Fracassados: O Imperativo do Sucesso na Cultura da Autoajuda. Curitiba: Appris.

Costa, J. F. (1999). Ordem médica e norma familiar. Rio de Janeiro: Edições Graal.

Del Priore, M. (2009). Ao sul do corpo: Condição feminina, maternidades e mentalidades no Brasil Colônia. 2. ed. São Paulo: Unesp.

Escosteguy, A. C. D. (Org.). (2008). Comunicação e gênero: a aventura da pesquisa. Porto Alegre: EdiPUCRS.

Figueiredo Souza, A. L. (28 abril, 2020). Maternidade no Brasil - Uma escolha? Cientistas Feministas. Recuperado de https://bit.ly/3h1Ejwa

Figueiredo Souza, A. L. (2019). "Me deixem decidir se quero ou não ser mãe!": narrativas pessoais de mulheres sobre a maternidade nas mídias sociais. (Tesis de maestría, Universidade Federal Fluminense, Niterói, Brasil). Recuperada de https://bit.ly/2MWxu1n

Freire, M. M. L. (2009). Mulheres, mães e médicos: discurso maternalista no Brasil. Rio de Janeiro: Editora FGV.

Giddens, A. (1991). Modernity and Self-identity: Self and Society in the Late Modern Age. Cambridge, UK: Polity Press.

Hammersley, M. \& Atkinson, P. (1983). Ethnography: Principles in practice. London: Tavistock. 
Herring, S. C. (2012). Discourse on Web 2.0: Familiar, reconfigured, and emergent. En: Tannen, D.; Trester, A.M. (Eds.). Discourse 2.0: Language and new media (pp. 16-41). Washington D.C.: Georgetown University Press.

Lemos, A. (2002). Cibercultura, tecnologia e vida social na sociedade contemporânea. Porto Alegre: Sulina.

Mendonça, M. C. (2014). A maternidade na publicidade: Uma análise qualitativa e semiótica em São Paulo e Toronto. (Tesis de doctorado, Pontifícia Universidade de São Paulo, São Paulo, Brasil). Recuperada de https://bit.ly/3bypLko

Orton-Johnson, K. (2017). Mummy Blogs and Representations of Motherhood: “Bad Mummies" and Their Readers. Social Media + Society, 3(2), 1-10, apr./jun. doi: 10.1177\%2F2056305117707186

Primo, A. (2007). 0 aspecto relacional das interações na Web 2.0. E-Compós, 9 (ago.), sin paginación. doi: 10.30962/ec.v9i0.153

San Cornelio, G. (2017). Visiones contemporáneas de la maternidad en Instagram: una aproximación mixta al estudio del selfie como narrativa personal. Rizoma, 5(2), 26-41. doi: $10.1177 / 256305117707186$

Scavone, L. (2004). “Dar a vida e cuidar da vida: sobre maternidade e saúde”. En: Scavone, L. (Ed.). Dar a vida e cuidar da vida: feminismo e ciências sociais. (pp. 127-139). São Paulo: Unesp.

Sibilia, P. (2016). O show do eu: A intimidade como espetáculo. 2. ed. Rio de Janeiro: Contraponto.

Van Zoonen, L. (2012). I-Pistemology: changing truth claims in popular and political culture. European Journal of Communication, 27(1), 56-67. doi: 10.1177/0267323112438808

- Sobre la autora:

Ana Luiza de Figueiredo Souza es Máster y doctoranda por el PPGCOM UFF. Licenciada en Comunicación Social -Publicidad y Propaganda por la UFRJ. Coordinadora de revisión de la Revista Contracampo. Miembro del grupo de investigación MiDICom. Colaboradora del proyecto Cientistas Feministas. Editora de textos y escritora.

\section{- ¿Cómo citar?}

Figueiredo Souza, A. L. (2020). Maternidad en las redes sociales de internet. Vivencias maternas brasileñas compartidas en red. Comunicación y Medios, (41), 54-66, doi: 10.5354/0719-1529.2020.54499 